IZADP No. 3513

Monetary Persistence and the Labor Market: A New Perspective

Wolfgang Lechthaler

Christian Merkl

Dennis Snower

May 2008 


\title{
Monetary Persistence and the Labor Market: A New Perspective
}

\author{
Wolfgang Lechthaler \\ Kiel Institute for the World Economy
}

Christian Merkl

Kiel Institute for the World Economy, University of Kiel and IZA

Dennis Snower

Kiel Institute for the World Economy, University of Kiel and IZA

Discussion Paper No. 3513
May 2008

IZA

P.O. Box 7240

53072 Bonn

Germany

Phone: +49-228-3894-0

Fax: +49-228-3894-180

E-mail: iza@iza.org

Any opinions expressed here are those of the author(s) and not those of IZA. Research published in this series may include views on policy, but the institute itself takes no institutional policy positions.

The Institute for the Study of Labor (IZA) in Bonn is a local and virtual international research center and a place of communication between science, politics and business. IZA is an independent nonprofit organization supported by Deutsche Post World Net. The center is associated with the University of Bonn and offers a stimulating research environment through its international network, workshops and conferences, data service, project support, research visits and doctoral program. IZA engages in (i) original and internationally competitive research in all fields of labor economics, (ii) development of policy concepts, and (iii) dissemination of research results and concepts to the interested public.

IZA Discussion Papers often represent preliminary work and are circulated to encourage discussion. Citation of such a paper should account for its provisional character. A revised version may be available directly from the author. 
IZA Discussion Paper No. 3513

May 2008

\section{ABSTRACT \\ Monetary Persistence and the Labor Market: A New Perspective*}

It is common knowledge that the standard New Keynesian model is not able to generate a persistent response in output to temporary monetary shocks. We show that this shortcoming can be remedied in a simple and intuitively appealing way through the introduction of labor turnover costs (such as hiring and firing costs). Assuming that it is costly to hire and fire workers implies that the employment rate is slow to converge to its steady state value after a monetary shock. The after-effects of a shock continue to exert an effect on the labor market even long after the shock is over. The sluggishness of the labor market translates to the product market and thus the output effects of the monetary shock become more persistent. Under reasonable calibrations our model generates hump-shaped output responses. In addition, it is able to replicate the Beveridge curve relationship and a negative correlation between job creation and job destruction.

JEL Classification: E24, E32, E52, J23

Keywords: monetary persistence, labor market, hiring and firing costs

Corresponding author:

Christian Merkl

Kiel Institute for the World Economy

Düsternbrooker Weg 120

24105 Kiel

Germany

E-mail: christian.merkl@ifw-kiel.de

\footnotetext{
* We would like to thank Marty Eichenbaum, Ester Faia, Keith Kuester, Camille Logeay, Christian Proano-Acosta, Roland Winkler and the participants of the IfW staff seminar, the FU Berlin research seminar and the LoWER workshop for very valuable suggestions. All remaining errors are our own.
} 


\section{Introduction}

This paper offers a novel framework which shows how the interaction of product and labor markets can generate considerable output persistence in reaction to a monetary shock. Labor turnover costs - which in this paper are represented by linear hiring and firing costs - lead to a sluggish adjustment in the labor market, even after the monetary impulse has disappeared. Labor turnover costs, needless to say, reduce the hiring and firing rates by making hiring and firing more costly. As a consequence, they reduce the levels of hiring and firing activity in the aftermath of a monetary shock. Sluggish labor market adjustment also leads to sluggish product market adjustment after a shock - more sluggish than in the standard New Keynesian models and in closer consonance with the empirical evidence. Furthermore, our model is able to replicate the Beveridge curve, which search-and-matching models with endogenous separations and flexible wages are unable to do. ${ }^{1}$ Our simulations show a stable negative relationship between vacancies and unemployment, both for monetary and productivity shocks.

It is well known that the standard small-scale New Keynesian framework with a representative household and neoclassical labor markets does not generate any monetary persistence when the central bank deviates in uncorrelated manner from the Taylor rule interest rate behavior. To overcome this problem medium scale DSGE models (e.g., Christiano et al., 2005, or Smets and Wouters, 2003, 2007) contain several assumptions which may be difficult to reconcile with microeconomic evidence (e.g., habit formation ${ }^{2}$ or backward-looking indexation $\left.^{3}\right)$.

Recently, imperfect labor markets have been identified as a potential missing link in the search for sources of monetary persistence. Several papers integrate search and matching frictions and ad-hoc real wage rigidities into the New Keynesian model (e.g., Blanchard and Galí, 2006, Faia, 2008, Christoffel and Linzert, 2006, Krause and Lubik, 2007). The focus of these papers is how real wage rigidity affects different aspects of the model outcome (e.g., monetary persistence, optimal monetary policy or the effects of disinflationary policies). Concerning the question whether real wage rigidities generate more monetary persistence, these papers are inconclusive. While Krause and Lubik, 2007, demonstrate the irrelevance of real wage rigidity, Christoffel and Linzert, 2006 , conclude that this channel is indeed important. Their differing results are due primarily to their different specifications of the households' preferences and different labor adjustment mechanisms ${ }^{4}$. In any case, the ad hoc specification of the real rigidities in the models above means that they do not sit comfortably within a microfounded general equilibrium model; microfounding these real wage rigidities may entail other changes in the general equilibrium model that

\footnotetext{
${ }^{1}$ See Krause and Lubik, 2007.

${ }^{2}$ Habit formation may be present for specific goods or services, but not for the entire consumption bundle, as it is generally assumed in medium scale models.

${ }^{3}$ There is little empirical microeconomic evidence for such indexation. See Woodford, 2007, for a discussion of this issue.

${ }^{4}$ While Krause and Lubik, 2007, only model the extensive margin, Christoffel and Linzert, 2006, also have the intensive margin.
} 
have significant effects on their predictions and policy implications.

Another serious shortcoming of the search and matching models with endogenous separations is demonstrated by Krause and Lubik, 2007. In their benchmark model without real wage rigidity, they cannot replicate the Beveridge curve and the negative correlation between job creation and job destruction - both of them are well-known stylized facts. By adding real wage rigidity, they obtain the Beveridge curve but not the negative correlation between job creation and destruction. ${ }^{5}$ In contrast, our model is able to replicate both empirical facts, without the adding any ad-hoc assumptions.

Our alternative labor market approach examines the influence of well-known labor turnover costs - costs of hiring and firing - on the effectiveness of monetary policy. ${ }^{6}$ Thus, the labor market rigidities of our model are microfounded and the monetary policy transmission mechanism has a straightforward intuition on that basis.

In the absence of labor turnover costs, a worker's current employment probability is independent of whether she was previously employed or unemployed, so that her retention rate is equal to her job finding rate. In the presence of hiring and firing costs, by contrast, her retention rate exceeds her job finding rate, and thus current employment depends on past employment. In this setting, a current monetary shock affects not only current, but also future, employment. Since labor is used to produce output, employment persistence is translated into output persistence.

Specifically, in the presence of a positive, temporary macroeconomic shock, workers are hired but, on account of firing costs, these workers are not promptly dismissed as soon as the shock is over. Thus the effects of the shock on employment and output persist. But even in the absence of firing costs, hiring costs create employment and output persistence. For instance, once a temporary positive shock has passed, some workers are retained who would not have been hired in the absence of this shock, due to hiring costs. Thus the positive shock has persistent after-effects. ${ }^{7}$ In this way, the inclusion of labor turnover costs - a simple, well-known, pervasive feature of labor markets - can be shown to explain how monetary shocks have prolonged effects on output and employment.

Although, for brevity, our analysis does not explicitly consider training costs, it is worth noting that on-the-job training costs generate employment and output persistence in the same way as hiring costs, since these training costs are simply hiring costs associated with a productivity increase. In fact, any labor turnover

\footnotetext{
${ }^{5}$ Another way to obtain a Beveridge curve would be to assume completely exogenous separations. However, this is clearly ad-hoc and it is then impossible to replicate the negative correlation between job creation and job destruction.

${ }^{6}$ Rotemberg and Woodford, 1999, analyze convex labor adjustment costs. But they focus solely on the implications of these costs for fluctuations of the markup over the business-cycle. Furthermore, their approach does not allow for unemployment.

${ }^{7}$ Alternatively, consider an employee whose productivity is just high enough to be retained. An unemployed worker with the same productivity will not be offered a job, however, due to the positive hiring cost. In short, hiring costs create persistence in the aftermath of a shock, because in the presence of hiring costs, the retention probability of employees exceeds the hiring probability of unemployed.
} 
costs (not just hiring, training and firing costs) can give rise to employment and output persistence through the channel identified in our analysis; such costs also include those associated with cooperation and harassment activities of insiders, ${ }^{8}$ and effort-related costs of labor turnover, ${ }^{9}$ and productivity risk. ${ }^{10}$ Since such labor turnover costs are a ubiquitous feature of all labor markets, our analysis has a wide relevance, well beyond those with stringent job security legislation and powerful unions.

We calibrate our model with moderate hiring and firing costs. Under uncorrelated iid monetary shocks, it takes several quarters until the economy returns to the steady state, while the standard model generates no persistence at all. When the monetary policy shock is moderately autocorrelated (e.g., with an autocorrelation coefficient of 0.4 ), we obtain hump-shaped output responses, without using any extra assumptions (such as habit formation). Thus labor adjustment costs offer a new explanation for output persistence, which has so far been largely unexplored.

The rest of the paper is structured as follows. Section 2 presents the theoretical model and Section 3 explains the calibration. Section 4 discusses the model outcomes. And Section 5 concludes.

\section{The Model}

Our model grafts a labor market with labor turnover costs, wage bargaining, and employed and unemployed workers onto a New Keynesian framework with Rotemberg adjustment costs. ${ }^{11}$ To endogenize hiring and firing decisions, it is assumed that the profitability of each worker is subject to an iid shock each period. Firms can change their price in any period but price changes are subject to quadratic adjustment costs. Monetary policy is represented by a Taylor rule.

\subsection{Households}

We assume that households have a standard utility function of the form: ${ }^{12}$

$$
U=\sum_{t=0}^{\infty} \beta^{t} \frac{c_{t}^{1-\sigma}}{1-\sigma},
$$

\footnotetext{
${ }^{8}$ To protect their jobs and avoid downward pressure on their wages, insiders often cooperate with one another but not with new entrants who attempt to underbid them. See Lindbeck and Snower (1988a).

${ }^{9}$ When current effort leads to future remuneration rewards (e.g., promotions), an increase in the rate of labor turnover within a firm means that the reward for current effort falls and this may induce employees to reduce effort. See Lindbeck and Snower (1988b).

${ }^{10}$ Firms generally know more about the productivity of their insiders than that of new entrants. Thus labor turnover comes with increased risk for the firm.

${ }^{11}$ The model with Calvo price staggering can be found in the Appendix. The results stay qualitatively the same.

${ }^{12}$ This is similar to the utility function in Krause and Lubik, 2007, except that we do not need money in the utility function, since we model monetary policy by a Taylor rule rather than by a money growth rule.
} 


\section{Stylized Model Structure}

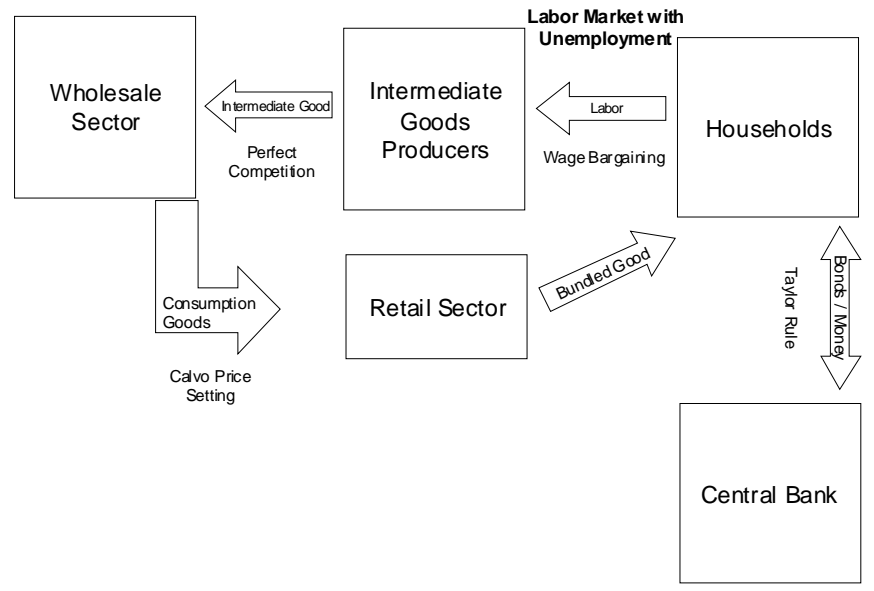

Figure 1: Model Structure

where $\beta$ is the household's discount factor, $\sigma$ the elasticity of intertemporal substitution and $c$ a consumption aggregate (described below). ${ }^{13}$

As is common in the literature, we assume that each household consists of a large number of individuals, each individual supplies one unit of labor inelastically and shares all income with the other household members. This implies that consumption does not depend on a worker's employment status. Thus the representative household maximizes its utility subject to the budget constraint:

$$
B o_{t}+c_{t} P_{t}-T_{t}=W_{t} N_{t}+B_{t} U_{t}+\left(1+i_{t-1}\right) B o_{t-1}+\Pi_{a, t},
$$

where $B o$ are nominal bond holdings, $P$ is the aggregate price level, $T$ are tax payments, $i$ is the nominal interest rate and $\Pi_{a}$ are nominal aggregate profits, which are transferred in lump-sum manner, $W$ is the nominal wage, $N$ is the total household labor input, $B$ the income of unemployed workers and $U$ the number of unemployed workers. The intertemporal utility maximization yields the standard consumption Euler equation:

$$
c_{t}=c_{t+1}\left(\left(1+i_{t}\right) \beta \frac{P_{t}}{P_{t+1}}\right)^{-\frac{1}{\sigma}} .
$$

\footnotetext{
${ }^{13}$ In what follows capital letters refer to nominal variables and small letters refer to real variables (i.e., detrended by the price level).
} 


\subsection{Production and the Labor Market}

There are three types of firms. (i) Firms that produce intermediate goods employ labor, exhibit linear labor adjustment costs (i.e. hiring and firing costs) and sell their homogenous products on a perfectly competitive market to the wholesale sector. (ii) Firms in the wholesale sector transform the intermediate goods into consumption goods and sell them under monopolistic competition to the retailers. They can change their price at any time but price adjustments are subject to a quadratic adjustment cost à la Rotemberg. (iii) The retailers, in turn, aggregate the consumption goods and sell them under perfect competition to the households. The structure of the model is illustrated in figure 1.

\subsubsection{Intermediate Goods Producers}

Intermediate good firms hire labor to produce the intermediate good $z$. Their production function is:

$$
z_{t}=a_{t} N_{t}
$$

where $a$ is technology and $N$ the number of employed workers. They sell the product at a relative price $p_{z, t}=P_{z, t} / P_{t}$, which they take as given in a perfectly competitive environment, where $P_{z}$ is the absolute price of the intermediate good and $P$ is the economy's overall price level.

The labor market approach follows Snower and Merkl, 2006, and Brown, Merkl and Snower, 2007, who model the labor market in a pure partial equilibrium setting, while we extend it to a general equilibrium setting. We assume that every worker (employed or unemployed) is subject to a random operating $\operatorname{cost} \varepsilon$, which is iid over workers and time. ${ }^{14}$

The firms learn the value of the operating costs of every worker at the beginning of a period and base their employment decisions on it, i.e. an unemployed worker with a favorable shock will be employed while an employed worker with a bad shock might be fired. Hiring and firing is not costless, firms have to pay linear hiring costs, $h$, and linear firing costs, $f$, both measured in terms of the final consumption good. Wages are determined by bargaining between insiders and the firm.

We assume the following sequence of decisions: First, the operating cost shock takes place. Second, median insiders and the intermediate goods firm bargain over the wage. And finally, firms make their hiring and firing decisions, taking the operating costs and the wages as given.

Thus, firms will only hire those workers who face low operating costs (see Figure 2) and fire those workers who face high operating costs. Note that the retention rate (i.e., 1 minus the firing rate) is always bigger than the firing rate. The hiring and firing costs drive a wedge between the hiring rate and the retention rate. Once workers are inside the firm, they are protected by firing

\footnotetext{
${ }^{14}$ The operating costs can be interpreted as a idiosyncratic shock to workers' productivity or costs, i.e. workers face different costs every period. Similarly, the operating costs could also be interpreted as a firm-specific idiosyncratic cost-shock.
} 


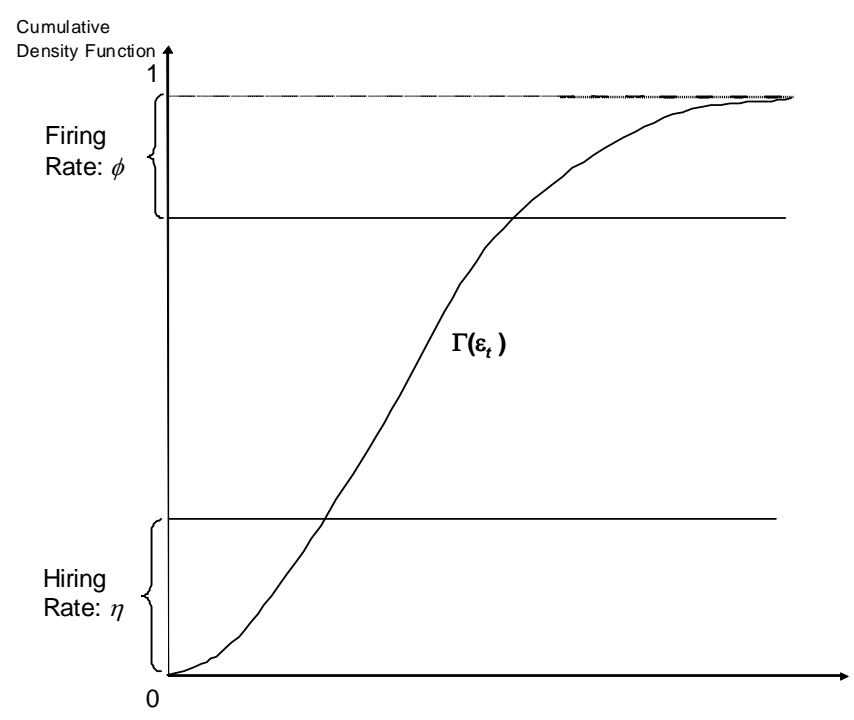

Figure 2: The effect of hiring and firing costs

costs (i.e., she will only be fired if her present value of profits is smaller than minus the firing costs), while the firm has to expense hiring costs to obtain a worker in the first place (i.e., she will only be hired if her present value of profits is bigger than the hiring costs).

The operating costs, $\varepsilon$, are measured in terms of the final consumption good and are assumed to grow at the same rate as productivity, $a$. It turns out that this ensures that technological progress does not affect the unemployment rate. ${ }^{15}$

Thus, the real profit generated by a worker with operating cost $\varepsilon_{t}$ is:

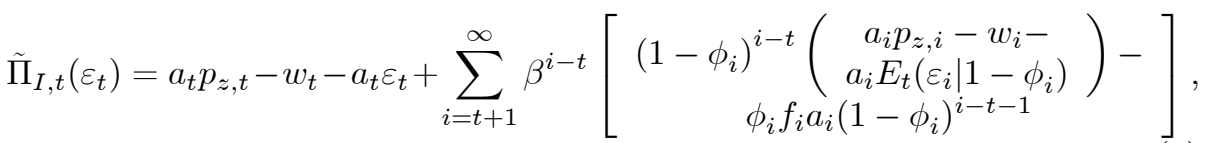

where $w$ is the real wage, $\phi$ is the separation probability and $E_{t}\left(\varepsilon_{t+1} \mid 1-\phi_{t+1}\right)$ the expected value of operating costs for an insider (i.e., conditional on retention),

\footnotetext{
${ }^{15}$ To see this, note that the profit function of an intermediate-goods firm (equation 7 ) is proportional to technology $a$ whenever the wage is proportional to $a$. Thus, given that hiring and firing costs are also proportional to $a$, the hiring and firing thresholds (and thereby hiring and firing rates) will not change with technological progress and thus unemployment is unaffected.
} 
given by:

$$
E_{t}\left(\varepsilon_{t+1} \mid 1-\phi_{t+1}\right)=\frac{1}{1-\phi_{t+1}} \int_{\infty}^{v_{f}} \varepsilon_{t+1} g\left(\varepsilon_{t+1}\right) d \varepsilon_{t+1} .
$$

where $g\left(\varepsilon_{t}\right)$ is the probability density function of the operating cost. To simplify the profit function we rewrite it in recursive manner:

$$
\tilde{\Pi}_{I, t}=a_{t} p_{z, t}-w_{t}-a_{t} \varepsilon_{t}+\beta E_{t}\left(\tilde{\Pi}_{I, t+1}\right),
$$

where $E_{t}\left(\tilde{\Pi}_{I, t+1}\right)$ are expected future profits, defined as:

$$
\begin{aligned}
E_{t}\left(\tilde{\Pi}_{I, t+1}\right)= & \left(1-\phi_{t+1}\right)\left(p_{z, t+1} a_{t+1}-w_{t+1}-a_{t} E_{t}\left(\varepsilon_{t+1} \mid 1-\phi_{t+1}\right)\right) \\
& +\left(1-\phi_{t+1}\right) \beta E_{t+1}\left(\tilde{\Pi}_{I, t+2}\right)-\phi_{t+1} a_{t+1} f_{t+1},
\end{aligned}
$$

Unemployed workers are hired whenever their operating cost does not exceed a certain threshold such that the profitability of this worker is higher than the hiring cost (see Figure 2 for the graphical illustration), i.e. $\tilde{\Pi}_{I, t}\left(\varepsilon_{t}\right)>a_{t} h_{t}$. Thus, the hiring threshold $v_{h, t}$ (the value of the operating cost at which the firm is indifferent between hiring and not hiring an unemployed worker) is defined by:

$$
\tilde{\Pi}_{I, t}\left(v_{h, t}\right)=a_{t} p_{z, t}-w_{t}-a_{t} v_{h, t}+\beta E_{t}\left(\tilde{\Pi}_{I, t+1}\right)=a_{t} h_{t} .
$$

Unemployed workers whose operating cost is lower than this value get a job, while those whose operating cost is higher remain unemployed. The resulting hiring probability is given by:

$$
\eta_{t}=\Gamma\left(v_{h, t}\right),
$$

where $\Gamma$ is the cumulative density function of $\varepsilon$. Similarly, the firm will fire a worker whenever $\tilde{\Pi}_{t}\left(\varepsilon_{t}\right)<-a_{t} f_{t}$, i.e. when the operating costs are so high that it is more profitable for the firm to pay the firing cost. This defines the firing threshold (the value of the operating cost at which the firm is indifferent between firing and retaining the worker) as

$$
\tilde{\Pi}_{I, t}\left(v_{f, t}\right)=a_{t} p_{z, t}-w_{t}-a_{t} v_{f, t}+\beta E_{t}\left(\tilde{\Pi}_{I, t+1}\right)=-a_{t} f_{t},
$$

and the separation rate is:

$$
\phi_{t}=1-\Gamma\left(v_{f, t}\right) .
$$

\subsubsection{Employment}

The change in employment $\left(\Delta N_{t}\right)$ is the difference between the hiring from the unemployment pool $\left(\eta U_{t-1}\right)$ and the firing from the employment pool $\left(\phi N_{t-1}\right)$, where $U_{t-1}$ and $N_{t-1}$ are the aggregate unemployment and employment levels: 
$\Delta N_{t}=\eta U_{t-1}-\phi N_{t-1}$. Letting $\left(n_{t}=N_{t} / L_{t}\right)$ be the employment rate, we assume a constant workforce, $L_{t}$, and normalize it to one. Therefore, we obtain the following employment dynamics curve.

$$
n_{t}=n_{t-1}\left(1-\phi_{t}-\eta_{t}\right)+\eta_{t}
$$

The unemployment rate is simply $u_{t}=1-n_{t}$.

\subsubsection{Wage Bargaining}

For simplicity, let the real wage $w_{t}$ be the outcome of a Nash bargain between the median insider with operating $\operatorname{cost} \varepsilon^{I}$ and her firm. The median insider faces no risk of dismissal at the negotiated wage. The wage is renegotiated in each period $t$. Under bargaining agreement, the insider receives the real wage $w_{t}$ and the firm receives the expected profit $\left(a_{t} p_{z, t}-w_{t}\right)$ in each period $t$. Under disagreement, the insider's fallback income is $a_{t} b_{t},{ }^{16}$ assumed for simplicity to be equal to the real unemployment benefit, $b_{t}$. The firm's fallback profit is zero, i.e. during disagreement there is no production. ${ }^{17}$ Assuming that disagreement in the current period does not affect future surpluses, the surplus of the worker is $\left(w_{t}^{1-\sigma}-\left(a_{t} b_{t}\right)^{1-\sigma}\right) /(1-\sigma)$ while the firm's surplus is $a_{t}^{I} p_{z}-w_{t}-a_{t} \varepsilon^{I}$, where $\varepsilon^{I}$ are the operating costs of the average insider. Consequently, the Nash-product is: ${ }^{18}$

$$
\Lambda=\left(\frac{w_{t}^{1-\sigma}-\left(a_{t} b_{t}\right)^{1-\sigma}}{1-\sigma}\right)^{\gamma}\left(a_{t}^{I} p_{z}-w_{t}-a_{t} \varepsilon^{I}\right)^{1-\gamma},
$$

where $\gamma$ represents the bargaining strength of the insider relative to the firm. Maximizing the Nash-product with respect to the real wage, yields the following equation:

$$
(1-\gamma)\left(\frac{w_{t}^{1-\sigma}-b_{t}^{1-\sigma}}{1-\sigma}\right)=\gamma\left(a_{t}^{I} p_{z}-w_{t}-a_{t} \varepsilon^{I}\right)\left(w_{t}\right)^{-\sigma},
$$

which implicitly defines the negotiated wage. ${ }^{19}$

\subsubsection{Wholesale Sector and Retail Sector}

Firms in the wholesale sector are distributed on the unit interval and indexed by $i$. They produce a differentiated good $y_{i, t}$ using the linear production technology $y_{i, t}=z_{i, t}$, where $z_{i, t}$ is their demand for intermediate goods. They sell their goods under monopolistic competition to the retailers who use the differentiated

\footnotetext{
${ }^{16}$ The unemployment benefit is assumed to grow at the same rate as technology $A$, to ensure that the wage is proportional to $A$, which in turn ensures that the unemployment rate is independent of technological progress.

${ }^{17}$ For more details on the wage bargaining approach see Brown, Merkl and Snower (2007).

${ }^{18}$ For a more detailed derivation of the wage, see the Appendix.

${ }^{19}$ As we calibrate the model nonlinearly to keep all relevant information, this formula does not have to be log-linearized.
} 
goods to produce the final consumption good according to the Dixit-Stiglitzaggregator:

$$
y_{t}=\left(\int y_{i, t}^{\frac{\varepsilon-1}{\varepsilon}} d i\right)^{\frac{\varepsilon}{\varepsilon-1}}
$$

which delivers the standard price index (where $P_{i, t}$ and $y_{i, t}$ denote the firm specific price and output level respectively):

$$
P_{t}=\left(\int P_{i, t}^{1-\varepsilon} d i\right)^{\frac{1}{1-\varepsilon}}
$$

from the cost minimization problem of the aggregating firm. The implied demand function for differentiated products is:

$$
y_{i, t}=y_{t}\left(\frac{P_{i, t}}{P_{t}}\right)^{-\varepsilon}
$$

Firms in the wholesale-sector can change their prices every period, facing quadratic price adjustment costs a la Rotemberg. They maximize the following profit function:

$$
\tilde{\Pi}_{W, t}=E_{t} \sum_{i=t}^{\infty} \beta^{i-t} \Delta_{t}\left[\frac{P_{i, t}}{P_{t}} y_{i, t}-p_{z, t} y_{i, t}-\frac{\Psi}{2}\left(\frac{P_{i, t}}{P_{i, t-1}}-\bar{\pi}\right)^{2} Y_{t}\right],
$$

where $\Psi$ is a parameter measuring the extent of price adjustment costs, $\bar{\pi}$ is the steady state inflation rate and $\Delta$ is stochastic discount factor (i.e. the subjective discount factor weighted with respective periods' marginal consumption utility). Taking the derivative with respect to the price yields after some manipulations the standard price-setting rule under Rotemberg adjustment costs:

$$
(1-\varepsilon) \Delta_{t}+\varepsilon \Delta_{t} p_{z, t}-\Delta_{t} \Psi\left(\pi_{t}-\bar{\pi}\right) \pi_{t}+\Delta_{t+1} \Psi \beta_{t+1}\left(\pi_{t+1}-\bar{\pi}\right) \frac{Y_{t+1}}{Y_{t}} \pi_{t+1}=0
$$

\subsection{Aggregation}

To be able to implement the resource constraint, we need to derive the sectors' profits. The real profits of intermediate firms $\left(\tilde{\Pi}_{I}\right)$ are revenues minus wage payments minus operating costs minus labor turnover costs:

$$
\begin{aligned}
\tilde{\Pi}_{I}= & p_{z, t} a_{t} n_{t}-w_{t} n_{t}-(1-\phi) n_{t} a_{t}\left(1-\Xi_{t}^{i}\right)- \\
& \left(1-n_{t}\right) \eta a_{t}\left(1-\Xi_{t}^{e}\right)-n_{t} \phi_{t} f_{t} a_{t}-\left(1-n_{t}\right) \eta_{t} h_{t} a_{t},
\end{aligned}
$$

where $\Xi_{t}^{i}$ is the expected value of operating costs for insiders, conditional on not being fired and $\Xi_{t}^{e}$ is the expected value of operating costs for entrants, conditional on being hired, defined by: 


$$
\begin{aligned}
& \Xi_{t}^{e}=\frac{\int_{-\infty}^{v_{h}} \epsilon_{t} f\left(\epsilon_{t}\right) d \epsilon_{t}}{\eta_{t}}, \\
& \Xi_{t}^{i}=\frac{\int_{-\infty}^{v_{f}} \epsilon_{t} f\left(\epsilon_{t}\right) d \epsilon_{t}}{1-\phi_{t}} .
\end{aligned}
$$

The real profits $\left(\tilde{\Pi}_{W}\right)$ of the monopolistic competitors (i.e., the wholesale sector) are:

$$
\tilde{\Pi}_{W}=y_{t}-p_{z, t} a_{t} n_{t},
$$

while the retailers make zero-profits. Hence overall real profits are given by:

$\tilde{\Pi}_{a, t}=y_{t}-w_{t} n_{t}-n_{t} \phi_{t} f_{t} a_{t}-u_{t} \eta_{t} h_{t} a_{t}-(1-\phi) n_{t} a_{t}\left(1-\Xi_{t}^{i}\right)-\left(1-n_{t}\right) \eta_{t} a_{t}\left(1-\Xi_{t}^{e}\right)$,

Substituting this into the resource constraint (2) (together with $B o_{t}=B o_{t-1}=$ 0 ), we get the relation between consumption and production:

$$
c_{t}=y_{t}-n_{t} \phi f_{t} a_{t}-\left(1-n_{t}\right) \eta_{t} h_{t} a_{t}-(1-\phi) n_{t} a_{t}\left(1-\Xi_{t}^{i}\right)-\left(1-n_{t}\right) \eta_{t} a_{t}\left(1-\Xi_{t}^{e}\right)
$$

The resource constraint tells us that aggregate consumption is equal to aggregate production minus aggregate labor turnover costs (since real resources are used for the labor turnover costs) minus aggregate operating costs.

\subsection{Monetary Policy}

Monetary policy follows a standard Taylor rule:

$$
\left(\frac{1+i_{t}}{1+\bar{\imath}}\right)=\left(\frac{\pi_{t}}{\bar{\pi}}\right)^{\alpha_{\pi}}\left(\frac{y_{t}}{y}\right)^{\alpha_{y}} e^{\lambda_{t}}
$$

where $\pi_{t}$ is the gross inflation rate (i.e., $\left.P_{t} / P_{t-1}\right), \bar{\pi}$ is the central bank inflation target, $y_{t}$ is the actual output, $y$ is the steady state level of output and $\bar{\imath}$ is the natural interest rate (for a given output and inflation level ${ }^{20}$ ). $\lambda_{t}$ is an exogenous shock to the Taylor rule.

\section{Model Calibration}

We parametrize our model, solve it nonlinearly to generate impulse response functions ${ }^{21}$ and log-linearize the system to analyze the second moments and

\footnotetext{
${ }^{20}$ Note that this term would drop out under a log-linearization.

${ }^{21}$ We solve our model nonlinearly to prevent a loss of information. In this, we follow Boucekkine, 1995, and Juillard, 1996. Further details on this approach can be found in Ascari and Merkl, 2008, footnote 10. Note that this strategy yields qualitatively the same results as the log-linearized version.
} 
correlations between different variables. We use a standard quarterly discount rate of one percent, $\beta=0.99$, and a log-utility of consumption, $\sigma=1$. The elasticity of substitution between different product types, $\varepsilon$, is set to 10 (see, e.g., Galí, 2003).

Table 1: Parameters of the Numerical Model

\begin{tabular}{|l||l|l|l|}
\hline Parameter & Description & Value & Source \\
\hline \hline$\beta$ & Subjective discount factor & 0.99 & Standard value \\
\hline$\sigma$ & Consumption utility & 1 & Log-utility \\
\hline$\varepsilon$ & Elasticity of subst. & 10 & Gali (2003) \\
\hline$\Psi$ & Price adjustment cost & 104.85 & Equivalent to $\theta=0.75$ \\
\hline$a$ & Productivity & 1 & Normalization \\
\hline$\gamma$ & Workers' bargaining power & 0.5 & Standard value \\
\hline$f$ & Firing cost & 0.6 & Bentolila and Bertola (1990) \\
\hline$h$ & Hiring cost & 0.1 & Chen and Funke (2003) \\
\hline$b$ & Unemployment benefits & 0.5 & OECD (2007) \\
\hline$E(\varepsilon)$ & Expected value of op. costs & 0.23 & To match the flow rates \\
\hline$s d$ & Distr. scaling parameter & 0.53 & To match the flow rates \\
\hline$\alpha_{\pi}$ & Taylor-rule & 1.5 & Standard value \\
\hline$\alpha_{y}$ & Taylor-rule & 0.125 & Standard value \\
\hline
\end{tabular}

As usual in the literature, we set the coefficients in the Taylor rule as follows: $\alpha_{\pi}=1.5$ and $\alpha_{y}=0.125 .^{22}$ We assume an autoregressive process for the shock, namely

$$
\lambda_{t}=\lambda_{t-1}^{\rho} \zeta_{t}
$$

where $\zeta_{t}$ is an i.i.d. shock. The autoregressive parameter, $\rho$, will be set to different values.

The parameter of price adjustments, $\Psi$, is calibrated in line with microeconometric evidence for Europe (see Alvarez et al., 2006). ${ }^{23}$ For simplicity, we normalize the yearly labor productivity to $a=1$. The bargaining power of workers, $\gamma$, is set to the standard value 0.5 .

We take continental Europe as our reference point. We set the firing costs to 60 percent $(f=0.6)$ of the annual productivity which amounts to approximately 88 percent of the annual wage. ${ }^{24}$ and the hiring costs to 10 percent $(h=$ $0.1)^{25}$ of annual productivity. We set the unemployment benefits to 50 percent

\footnotetext{
22 See Galí (2008, p. 83).

${ }^{23}$ Thus, the log-linearized Phillips curve under Calvo price adjustment under an average price duration of four quarters $(\theta=0.75$, see Appendix) and under our chosen calibration for Rotemberg adjustment costs are equivalent.

${ }^{24}$ For the period from 1975 to 1986 Bentolila and Bertola (1990) calculate firing costs of 92 percent, 75 percent and 108 percent of the respective annual wage in France, Germany and Italy respectively. The OECD (2004) reports that many European countries have reduced their job security legislation somewhat from the late 1980 to 2003 (in terms of the overall employment protection legislation strictness). Therefore, we consider $f=0.6$ to be a realistic number for continental European countries.

${ }^{25}$ See Chen and Funke, 2003.
} 
of the level of productivity $(b=0.5)$. This implies, that in steady state the wage replacement rate is roughly 73 percent, which is in line with evidence for continental European countries (see OECD, 2007).

Operating costs are assumed to follow a logistic distribution. ${ }^{26}$ The two parameters of the distribution $(E(\varepsilon)$ and $s d)$ are chosen in such a way that the resulting labor market flow rates match the empirical hiring and firing rates described further below. This yields an expected value of $E(\varepsilon)=0.23$ and a scale parameter of 0.53 .

We calibrate our flow rates using evidence for West Germany, as there are only Kaplan-Meier functions for individual countries. ${ }^{27}$ But we will show further below that these flow numbers are line with other important continental European countries. Wilke's, 2005, Kaplan-Meier functions indicate that about 20 percent of the unemployed leave their status after one quarter. For a steady state unemployment rate of 9 percent, a quarterly job finding rate of 2 percent is necessary. This is roughly in line with Wilke's estimated yearly risk of unemployment.

The used flow numbers are in line with the OECD, 2004, numbers for other continental European countries. ${ }^{28}$ We conclude that a quarterly job hiring rate of $\eta=0.20$ and a firing rate of $\phi=0.02$ are reasonable averages for continental European countries.

\section{Labor Turnover Costs and Output Persistence}

This section demonstrates how labor turnover costs affect the response of output to monetary shocks. In a first step, we consider an uncorrelated iid shock to the central bank's Taylor rule. And in a second step, we consider shocks with various degrees of autocorrelation. The third part of this section further illustrates the role of labor turnover costs on output persistence.

\subsection{One-Off Shock}

Let us assume that there is a one-off expansionary shock to the central bank's Taylor rule (i.e. the nominal interest goes down during the impact period). ${ }^{29}$ In the standard New-Keynesian model (see Galí, 2003) ${ }^{30}$ this kind of shock

\footnotetext{
${ }^{26}$ The probability density function of a logistic distribution is $g(\varepsilon)=\frac{e^{-(\varepsilon-E(\varepsilon)) / s d}}{s\left(1+e^{-(\varepsilon-E(\varepsilon)) / s d}\right)^{2}}$, where $E(\varepsilon)$ is the expected value of the operating costs and $s d$ is the scale parameter of the distribution.

${ }^{27}$ We choose the Kaplan-Meier functions for Germany, as it is the largest continental European country.

${ }^{28}$ Although the numbers of the OECD outlook are not directly applicable to our model, since they are built on a monthly basis, it is possible to adjust them using a method described in Shimer, 2007.

${ }^{29}$ Note that this shock is observationally equivalent to a shock to the central bank's inflation target, as it can be found for example in Smets and Wouters (2003).

${ }^{30} \mathrm{Log}$-linearized the standard model consists of a forward looking IS equation, the New Keynesian Phillips curve and a Taylor rule. However, for comparability we also solve it
} 

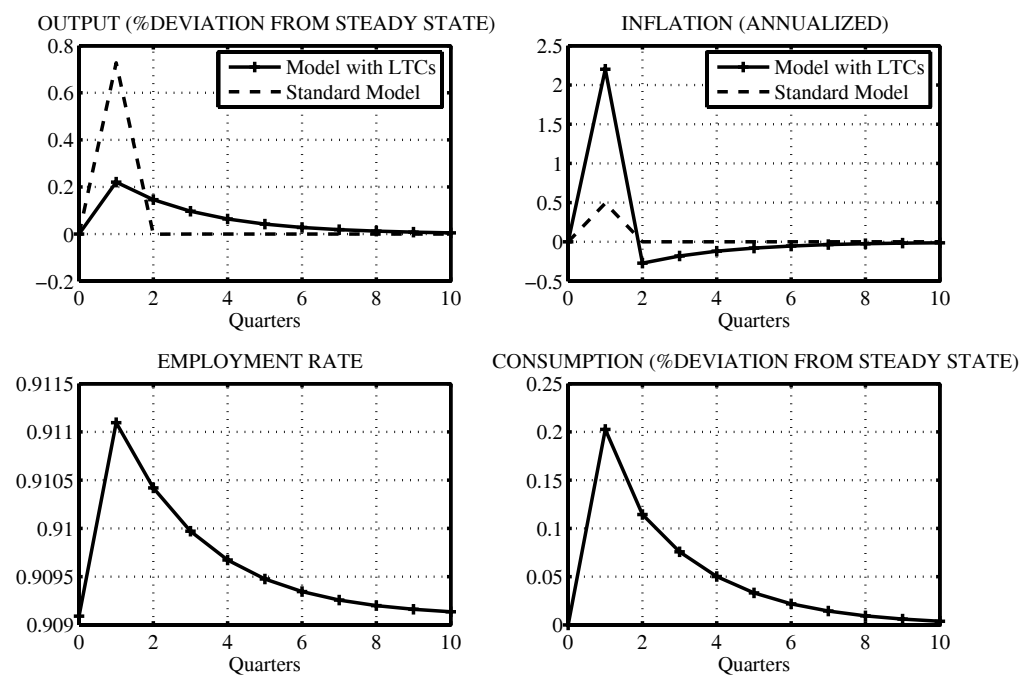

Figure 3: Reaction to an uncorrelated shock in the model with LTCs and in the standard model

generates no persistent change in output or inflation. The variables jump during the impact period and immediately return to their steady state values afterwards (see Figure 3). In the figure it can also be seen that the reaction is different under the new proposed model structure with LTCs. It turns out that hiring and firing costs create considerable persistence in the output response (see part 3 of this Section for further numerical illustrations). The figure also hints at the source of persistence. The slow adjustment of employment drives the result.

As usual, an expansionary shock lowers the real interest rate (as the nominal interest rate was adjusted downwards by the central bank and firms cannot adjust their prices flexibly). Therefore, households increase their demand for consumption goods (see consumption Euler equation). To satisfy the bigger demand, firms have to increase their workforce. They can do so, via two different channels, by hiring more workers and firing fewer workers. ${ }^{31}$ Since this is costly the initial response is more dampened than in a model without labor turnover costs.

Even though the shock has disappeared after the first period, it shows longlasting after-effects. Some of the workers who are below the firing threshold

\footnotetext{
nonlinearly.

${ }^{31}$ It is well known in the literature that the extensive margin plays the dominant role for business cycle adjustment compared to the intensive margin. Hansen (1985) shows that 55 percent of the variation in hours worked is due to variations in the number of employed people, while only 20 percent can be directly attributed to the average hours worked (the rest is due to the covariance term). Thus, the adjustment mechanism in our model is in line with this evidence. The underlying reason is that employment changes on the intensive margin are also associated with costs, namely, the costs of overtime.
} 
generate no profit for the firm (i.e., they would not be hired if they were not already within the firm), but it is not worthwhile to fire them, as the expected loss is smaller than the firing costs which would have to be expended. In this way, labor adjustment costs create a sluggish employment adjustment, which affects other markets in a general equilibrium setting.

Note that, in the context of the simplistic model above, inflation increases sharply in the first period and then undershoots its long-run equilibrium value. ${ }^{32}$ This counterfactual result is no longer present, when monetary shocks are sufficiently autocorrelated, as shown in the next section. ${ }^{33}$

\subsection{Persistent Shock}

As it is more realistic, we now turn to monetary shocks with an autoregressive component $\rho .{ }^{34}$ Our shocks can also be interpreted as a persistent shock to the inflation target, such as in Smets and Wouters (2003). ${ }^{35}$

While autocorrelated shocks are necessary to generate output persistence in the standard model, in our model they are sufficient to generate a humpshaped response in output (see Figure 4). This feature is especially attractive, given that empirical studies typically find a hump-shape in output (see, e.g., Christiano et al., 2005, and Smets and Wouters, 2003).

Under the chosen calibration, an autocorrelation of $\rho=0.35$ is sufficient to generate a hump-shaped response of output. However, we set the autocorrelation to $\rho=0.8$, as this is more in line with empirical evidence. (see, e.g., Fève, Matheron and Poilly, 2007). ${ }^{36}$

Again the reason for this result lies in labor turnover costs. In the standard

\footnotetext{
${ }^{32}$ Since intermediate goods producers have the biggest employment adjustment during the shock period, marginal costs - and with it inflation - increase accordingly. Subsequently, firing increases and hiring falls, as the firm's employment gradually converges to its steady state. A lower hiring rate increases the quality of entrants, which manifests in lower operating costs. The higher firing improves the quality of insiders, as only the more productive workers are retained. Both effects reduce marginal cost in the aftermath of the shock and thus inflation undershoots.

${ }^{33}$ Other common assumptions, such as backward indexing, would also avoid this implication.

${ }^{34}$ Although it is more common in the theoretical literature to assume interest rate smoothing, Rudebusch $(2002,2006)$ shows that the latter is empirically inconsistent with the interest term structure. Rudebusch (2002, p. 1182) writes: "Only the serially correlated shocks rule is consistent with the historical evidence showing that the term structure is largely uninformative about the future course of the policy rate." Following his argument, we assume an autocorrelation of shocks. Rudebusch (2002) writes that there may be both interest rate smoothing and the autocorrelation of shocks. Combining both mechanisms in our theoretical model would make our quantitative results even more pronounced. However, for simplicity and tractability, we focus on the autocorrelated component of shocks.

${ }^{35}$ The estimated autoregressive part of this shock is somewhat above the values which we use below.

${ }^{36}$ Fève, Matheron and Poilly (2007) show that it is difficult to identify whether the central bank performs interest rate smoothing or whether the shock is autocorrelated. They identify two optima for Europe, one for an autocorrelation of the shock $\rho=0.53$ and the other one for $\rho=0.95$. Note that these two values imply interest rate smoothing of the central bank. We do not use any interest rate smoothing, which would generate additional persistence. Instead, we restrain ourselves to one of these mechanisms to be able to illustrate our point better.
} 

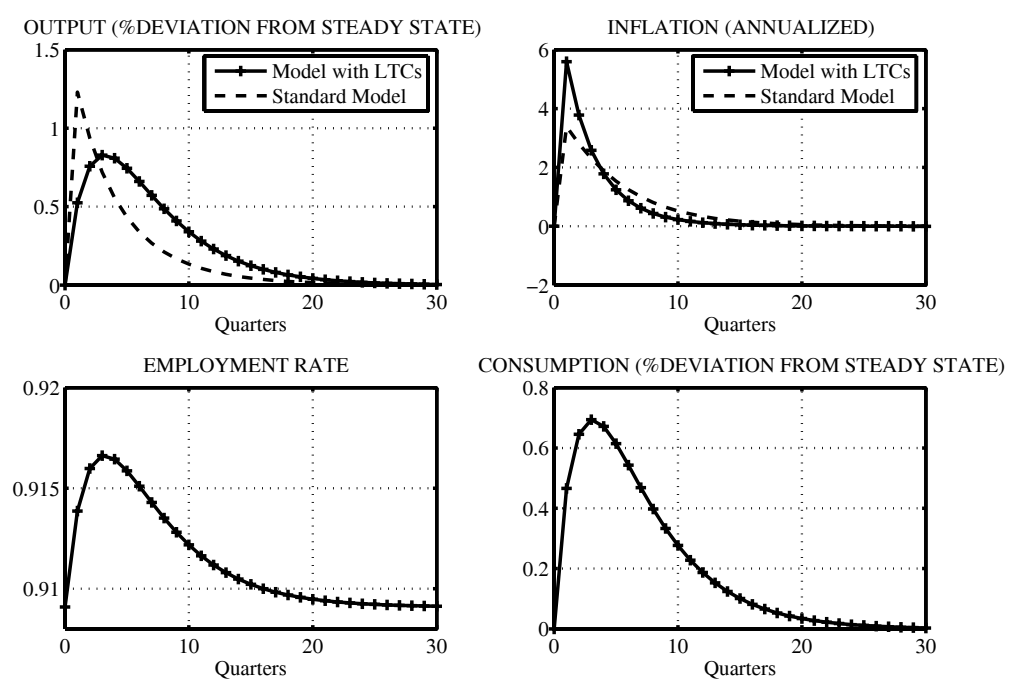

Figure 4: Model reaction with an autocorrelated shock $(\rho=0.8)$ for the standard model and the model with LTCs.

model without any adjustment costs, the output jumps up to its highest level in the first period and then slowly converges back to its steady state level, oneto-one with the movement in the interest rate which is purely driven by the autoregressive structure of the shock. Under positive labor turnover costs, the initial reply is dampened by adjustment costs, because increasing employment is more costly.

Given the autocorrelation in the shock, rational agents know that the central bank will persistently deviate from its monetary rule for several periods. The work force is extended considerably during the shock period. ${ }^{37}$ As the work force is already quite large after the shock impact period, a further increase in employment is possible at a lower cost than before. Once the firm has hired all these additional workers, it would be costly to fire them immediately (i.e., there is kind of a lock-in effect). Even though some of the workers may face considerable operating costs (i.e., with their given operating costs they would not be hired), it is not worthwhile for the firm to fire them, as their present value of profits is bigger than the firing costs.

Thus, even though the relative price of the intermediate good $\left(p_{z}\right)$ goes back in the second period, if the shock has a sufficiently big autocorrelation, there is an incentive for the firm to produce more output during the second period

\footnotetext{
${ }^{37}$ The intermediate goods producers act in a competitive sales market, i.e. they are price takers. Thus, strictly speaking they do not decide about the level of output. But their marginal costs are reflected in the relative price of the intermediate good $\left(p_{z}\right)$ which increases after the shock, thereby generating feedback effects on the price setting behavior of the wholesale sector and all other markets.
} 

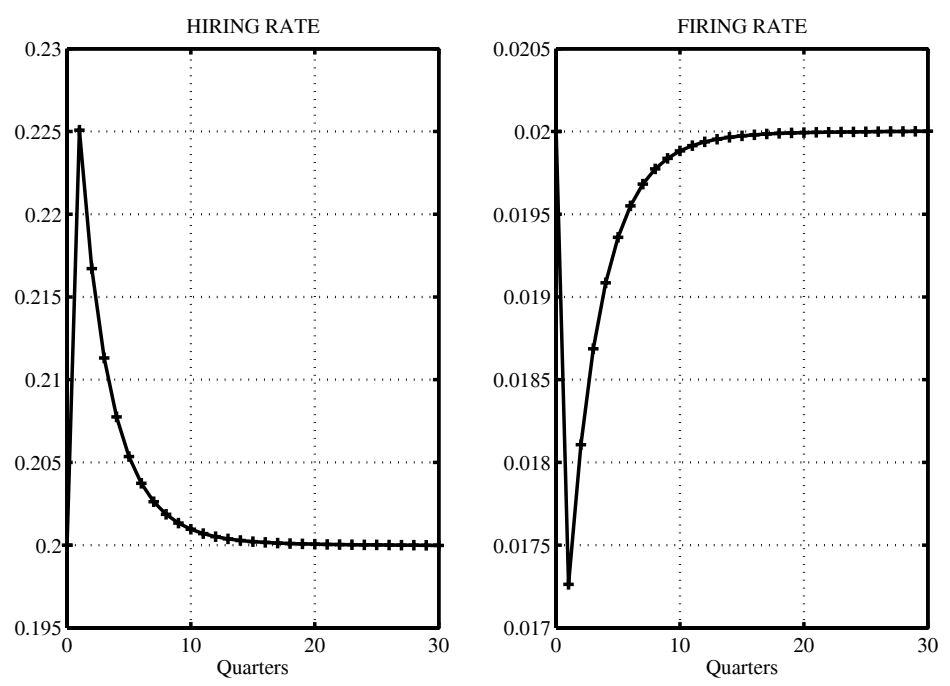

Figure 5: Hiring and firing rates

(due to the increased workforce during the first period which produces bigger capacities which are costly to adjust). ${ }^{38}$

Of course, in general equilibrium all these relationships are also reflected in other markets. Under higher autocorrelations, the real interest rate starts to behave in hump-shaped manner as well. As a consequence, starting with autocorrelations of around $\rho=0.45$, the consumption behavior (which is driven by the consumption Euler equation) also becomes hump-shaped (see Figure 4).

The bigger the autocorrelation of the shock is, the smaller is the undershooting problem of inflation and if the autocorrelation is high enough, inflation will converge from above back to its steady-state value. Why is this so? Due to the persistence of the shock the downward adjustment becomes very sequential, implying that the firing rate and the hiring rate move more smoothly.

If the central bank attaches no weight to output (i.e., $\alpha_{y}=0$, see Figure 6), the magnitude of the output response increases both in the standard model and in the model with labor turnover costs. In addition, the hump-shape is more pronounced in the model with LTCs. The reason can be found in the central bank's behavior. If it is only concerned about inflation stabilization, it will not worry about the hump-shaped deviation of output from its natural level. Therefore, the inflation reacts much smoother than under combined inflation

\footnotetext{
${ }^{38}$ There is a second effect that strengthens the hump shape of output. Under a nonlinear calibration, the price dispersion term, $s$, does not drop out, as it would be the case under a typical first-order Taylor approximation. Price distortions are very considerable in the after-math of the shock and make the economy less productive, while this effect is reduced afterwards. This phenomenon explains why the labor input shows less of a hump shape than the output.
} 

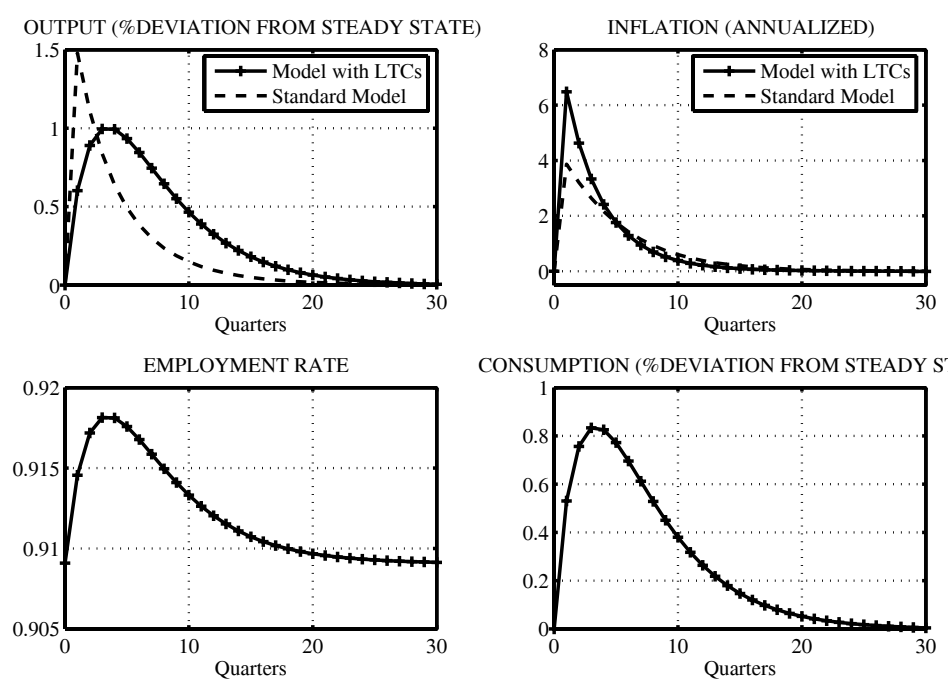

CONSUMPTION (\%DEVIATION FROM STEADY STATE)

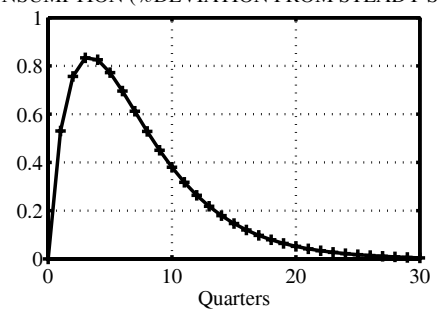

Figure 6: Model reaction with no weight on output and with an autocorrelated shock $(\rho=0.8)$ for the standard model and the model with LTCs.

and output targeting.

\subsection{The Effect of Different Labor Turnover Costs}

While we have shown so far that other than the standard model, the model with labor turnover costs is able to generate considerable output persistence, in this section we illustrate the direct effect of different labor turnover costs. In our model, labor turnover costs have two effects. First, they change the steady states. Lower labor turnover costs lead to higher employment rates and more production. This corresponds to the observation that the United States have higher employment rates and lower labor turnover costs than Europe. ${ }^{39}$ Second, as will be shown below, labor turnover costs increase output persistence in response to a monetary shock.

To illustrate that, we compare our standard calibration with an economy where firing costs are somewhat lower and somewhat higher than in the baseline calibration (i.e., 50 and 70 percent of the annual wage respectively instead of 60 percent as before), keeping all other deep parameters constant. For comparability reasons (as there are steady state movements), we express all the effects in terms of percentage deviations from the respective steady state.

\footnotetext{
${ }^{39}$ Under the given model structure, the employment rate does not generally increase with lower firing costs. For the chosen calibration this is however the case, as the hiring rate reacts more elastically than the firing rate (due to the calibration of the operating costs). This feature is in line with recent empirical evidence, which shows that hiring is more important than firing to explain the business cycle dynamics (see, e.g., Shimer, 2005).
} 


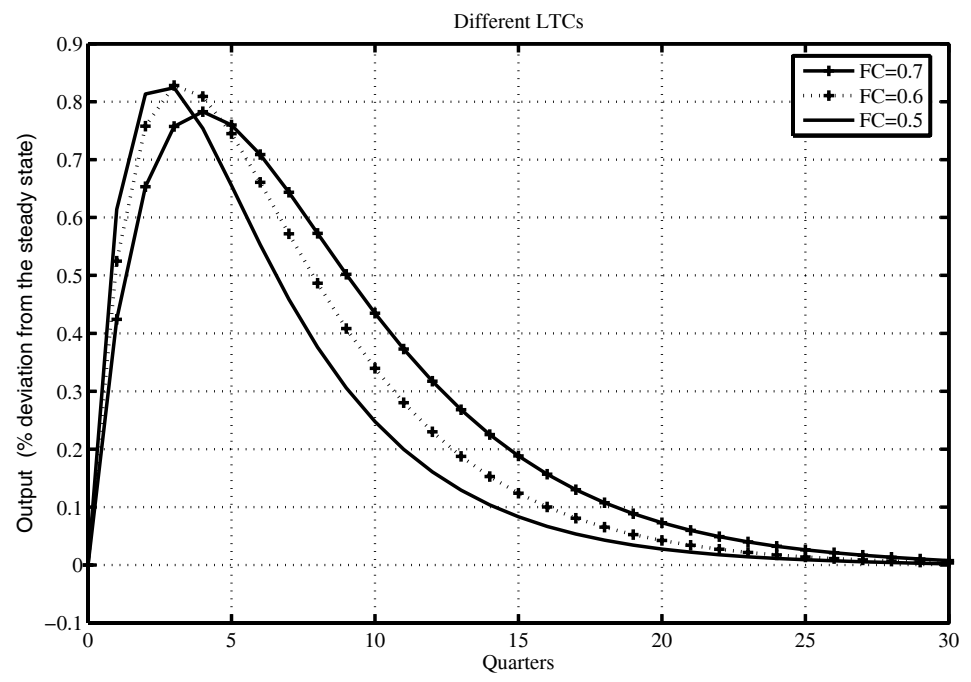

Figure 7: The effect of different firing costs

Figure 7 shows that higher labor turnover costs lead to more output persistence. The bigger the firing costs are, the more hump-shaped is the output response. While the adjustment during the impact period is more pronounced in an economy with lower labor adjustment costs, the economy also returns more quickly to the steady state (i.e., shows less persistence). The adjustment is slowed down by the labor turnover costs.

The critical reader may argue that our model is only relevant for European countries, because US enterprises typically face much lower firing costs. But our model is not a model of firing costs but a model of labor turnover costs. Training and hiring costs are present in all labor markets and not only eurosclerotic ones. And these costs lead to qualitatively the same effects as firing costs (i.e., higher hiring costs increase the output persistence), because they also drive a wedge between the job finding rate (i.e., the probability of leaving unemployment) and the retention rates (i.e., the probability of leaving employment). Once a worker is inside the firm, his retention probability will be bigger than his job finding probability (if he had not been hired before). Therefore, it takes longer until the labor market adjusts to the steady state and the output response becomes more persistent.

Given that firing costs are higher in Europe than in the United States, our model would then predict that persistence is higher in Europe than in the US, while econometric studies show a very similar pattern of the output response to a monetary policy shock (persistent and hump-shaped responses in both cases). One way to resolve this puzzle would be to consider realistic countervailing effects (which, for brevity, we have not included in the model above). For example, it can be shown that the more competitive are product markets, the greater 
is the corresponding degree of the output persistence in response to monetary shocks. Specifically, the greater is the elasticity of substitution among products (reducing each firms degree of monopoly power in the product markets), the smaller is the firm-specific price increase ${ }^{40}$ relative to the average market price $^{41}$, in response to a positive monetary shock (since price deviations will lead to larger demand fluctuations under a more competitive product market and since these demand fluctuations diminish the present value of profits. ${ }^{42}$ ). Thus, the price adjustment will be more muted and, correspondingly, the output response is more persistent. ${ }^{43}$ Since product markets in the US generally considered more competitive than those in Europe, on average, this mechanism thus would be one way to reconcile our model with the empirical evidence.

Morevoer, it would be premature to believe that the empirical literature has resolved question about whether monetary shocks are equally persistent in Europe and the US. In recent studies in this area, the microeconomic structure of estimated medium scale models for Europe and the United States (Smets and Wouters, 2003, and 2007) is specified in a similar manner. Thus these studies examine the data with the same priors on the labor market structure, this may be responsible for the fact that these estimate models generate similar amounts of monetary persistence for Europe and the United States. It remains for future research to examine whether the specification of different labor market structures in Europe and the United States - reflecting differences in labor market institutions in these areas - may lead to different results concerning comparative monetary persistence.

In any case, the issue of comparative monetary persistence is important for a variety of recent New Keynesian models aside from ours above. For example, it is commonly held that European labor markets exhibit more real wage rigidity than American ones, and thus models of monetary persistence based on real wage rigidities (such as those of Blanchard and Gali, 2007, and Christoffel and Linzert, 2006) imply that there should be more inflation persistence in Europe than in the U.S. Furthermore, micro-econonometric studies suggest a higher degree of price stickiness in Europe than in the United States (compare, for example, Bils and Klenow, 2004, and Alvarez et al., 2006), and this, too, has implications for the comparative degree of monetary persistence.

\footnotetext{
${ }^{40}$ For those firms who can re-adjust their prices according to the staggering scheme (either Calvo or Taylor).

${ }^{41}$ Under the assumption of diminishing returns, which can be modeled in terms of fixed capital and diminishing returns to labor or in terms of firm-specific capital.

${ }^{42}$ This holds under diminishing returns the production level is relevant for the marginal costs of the firm.

${ }^{43}$ See, for example, Merkl and Snower, 2008, for more details.
} 


\section{The Beveridge Curve and Business Cycle Cor- relations}

The Beveridge curve, i.e. the negative correlation between unemployment and vacancies over the business cycle, is one of the most prominent stylized facts about the labor market. However, as Krause und Lubik, 2007, demonstrate, a standard search-and-matching model with endogenous separations is not able to replicate it, neither in response to monetary shocks nor in response to productivity shocks. The search and matching model with endogenous separations is also unable to reproduce the negative correlation between job-finding and separation rates. By adding real wage rigidity the performance of the labor market can be improved somewhat: The Beveridge curve can be accomplished but not the negative correlation between job-findings and separations.

In contrast, even without the addition of any ad-hoc assumptions, our model shows a very strong Beveridge curve $^{44}$ for both monetary and productivity shocks, namely -0.71 for the former ${ }^{45}$ and -0.87 for the latter. ${ }^{46}$

Furthermore, our model generates a very strong negative correlation between job creation and job destruction. ${ }^{47}$ Thus, our model has the big advantage of replicating important stylized labor market facts.

\section{Conclusion}

The recent interest in the role of labor markets in the transmission of monetary policy offers a variety of new empirical and theoretical research questions. This paper offers a new (so far unexplored) labor market mechanism which assigns an important role to labor markets in the transmission of monetary policy. In contrast to the standard smale scale model, our model generates output persistence in response to uncorrelated monetary shocks (deviations from the central bank's systematic rule). Under moderately autocorrelated shocks, the output reacts in hump-shaped manner to monetary shocks. Hiring and firing costs reduce labor market flows. As a consequence, with higher labor turnover costs, the labor market's reaction to a monetary shock is more sluggish. The slow reaction of the labor market is transmitted to the product market and thereby generates a persistent output reaction.

Furthermore, our proposed model is consistent with important business cycle facts. It is able to generate a strong Beveridge curve relationship (both for productivity and interest rate shocks) and a negative correlation between job creation and job destruction.

\footnotetext{
${ }^{44}$ We use the hiring threshold as a proxy for vacancies. In the search and matching model, the firm has to post more vacancies to hire additional workers, while in our model, the hiring threshold has to be increased to obtain extra workers.

${ }^{45}$ Under an autocorrelation of the shock of $\rho=0.8$. The Beveridge curve relationship also holds for lower autocorrelations and uncorrelated shocks.

${ }^{46} \mathrm{With}$ an assumed autocorrelation for the productivity shock of 0.95 .

${ }^{47}$ In our simple set-up the correlation is -1 . Lower correlations could easily be generated, e.g., by introducing job destruction shocks.
} 


\section{References}

Alvarez, Luis J., Dhyne, Emmanuel, Hoeberichts, Marco, Kwapil, Claudia, Le Bihan, Hervé, Lünnemann, Patrick, Martins, Fenando, Sabbatini, Roberto, Stahl, Harald, Vermeulen, Philip, and Vilmunen, Jouko (2006): "Sticky Prices in the Euro Area: A Summary of New Micro-Evidence." Journal of the European Economic Association, Proceedings, Vol. 4, No. 2-3, pp. 575-584.

Ascari, Guido, and Merkl, Christian (2008): "Real Wage Rigidities and the Cost of Disinflations." Journal of Money, Credit, and Banking, forthcoming.

Bentolila, Samuel and Bertola, Giuseppe (1990): "Firing Costs and Labour Demand: How Bad is Eurosclerosis." Review of Economic Studies, Vol. 57, pp. 381-402.

Bils, Mark, and Klenow, Peter (2004): "Some Evidence on the Importance of Sticky Prices." Journal of Political Economy, Vol. 112, No. 5, pp. $947-985$.

Blanchard, Olivier, and Gali, Jordí (2007): "A New Keynesian Model with Unemployment." Kiel Working Paper, No. 1335, June 2007.

Boucekkine, Raouf (1995): "An Alternative Methodology for Solving Nonlinear Forward-Looking Models." Journal of Economic Dynamics and Control, Vol. 19, No. 4, pp.711-734

Brown, Alessio, Merkl, Christian, and Snower, Dennis (2007): "Comparing the Effectiveness of Employment Subsidies." IZA Discussion Paper, No. 2835, June 2007.

Chen, Yu-Fu, and Funke, Michael (2003): "Labour Demand in Germany: An Assessment of Non-Wage Labour Costs." CESifo Working Paper, No. 952, May 2003.

Christiano, Lawrence J., Martin Eichenbaum, and Charles Evans (2005): "Nominal Rigidities and the Dynamic Effects of a Shock to Monetary Policy." Journal of Political Economy, Vol. 113, No. 1, pp. 1-45.

Christoffel, Kai P., and Linzert, Tobias (2006): "The Role of Real Wage Rigidity and Labor Markt Frictions for Unemployment and Inflation Dynamics." Bundesbank Discussion Paper, Economic Research Centre: Series 1, No. 11/2006, April 2006.

Faia, Ester (2008): "Optimal Monetary Policy Rules with Labor Market Frictions." Journal of Economic Dynamics and Control, forthcoming.

Fève, Patrick, Matheron, Julien, and Poilly, Céline (2007): "Monetary Policy Dynamics in the Euro Area." Economics Letters, Vol. 96, No. 1, pp. 97-102. 
Galí, Jordi (2008): "Monetary Policy, Inflation, and the Business Cycle: An Introduction to the New Keynesian Framework." Princeton University Press.

Galí, Jordi (2003): "New Perspectives on Monetary Policy, Inflation, and the Business Cycle." In: Dewatriport, Mathias, Hansen, Lars P., and Turnovsky, Stephen J. (Eds), Advances in Economics and Econometrics: Theory and Applications, eighth World Congress, 2003, pp. 151-197.

Hall, Robert (2005): "Employment Fluctuations with Equilibrium Wage Stickiness." American Economic Review, Vol. 95, No. 1, pp. 50-65.

Hansen, Gary D. (1985): "Indivisible Labor and the Business Cycle." Journal of Monetary Economics, Vol. 16, pp. 309-327.

Juillard, Michel (1996): "Dynare: A Program for the Resolution and Simulation of Dynamic Models with Forward Variables." CEPREMAP Working Paper, No. 9602.

Krause, Michael U., and Lubik, Thomas A. (2007): "The (Ir)relevance of Real Wage Rigidity in the New Keynesian Model with Search Frictions." Journal of Monetary Economics, Vol. 54, No. 3, pp. 706-727.

Lindbeck, Assar, and Snower, Dennis (1988a): "Cooperation, Harassment and Involuntary Unemployment." American Economic Review, Vol. 78, No. 1, pp. 167-188;

Lindbeck, Assar, and Snower, Dennis (1988b): "Job Security, Work Incentives and Unemployment." Scandinavian Journal of Economics, Vol. 90, No. 4, pp. 454-474.

Merkl, Christian, and Snower, Dennis (2008): "Monetary Persistence, Imperfect Competition, and Staggering Complementarities." Macroeconomic Dynamics, forthcoming.

OECD (2007): "Benefits and Wages: OECD Indicators 2007." Organization for Economic Cooperation and Development, Paris.

OECD (2004): "OECD Employment Outlook 2004." Organization for Economic Cooperation and Development, Paris.

Rotemberg, Julio, and Woodford, Michael (1999): "The Cyclical Behavior of Prices and Costs." Handbook of Macroeconomics, Vol. 1B, pp. 1051-1135.

Rudebusch, Glenn (2006): "Monetary Policy Inertia: Fact or Fiction?" International Journal of Central Banking, Vol. 2, No. 3, pp. 85-135.

Rudebusch, Glenn (2002): "Term Structure Evidence on Interest Rate Smoothing and Monetary Policy Inertia." Journal of Monetary Economics, Vol. 49, pp. 1161-1187. 
Shimer, Robert (2007): "Reassessing the Ins and Outs of Unemployment." NBER Working Paper, No. 13421, September 2007.

Shimer, Robert (2005): "The Cyclical Behavior of Equilibrium Unemployment and Vacancies." American Economic Review, Vol. 95, No. 1, pp. $25-49$.

Smets, Frank, and Wouters, Rafael (2007): "Shock and Frictions in US Business Cycles: A Bayesian DSGE Approach." American Economic Review, Vol. 97, No. 3, pp. 586-606.

Smets, Frank, and Wouters, Rafael (2003): "An Estimated Dynamic Stochastic General Equilibrium Model of the Euro Area." Journal of the European Economic Association, Vol. 1, No. 5, pp. 1123-1175.

Snower, Dennis and Merkl, Christian (2006): "The Caring Hand that Cripples: The East German Labor Market after Unification." American Economic Review, Papers and Proceedings, Vol. 96, No. 2, pp. 375-382.

Trigari, Antonella (2004): "Equilibrium Unemployment, Job Flows and Inflation Dynamics." European Central Bank, Working Paper, No. 304, February 2004.

Wilke, Ralf (2005): "New Estimates of the Duration and Risk of Unemployment for West-Germany." Journal of Applied Social Science Studies, Vol. 125, No. 2, pp. 207-237.

Woodford, Michael (2007): "Interpreting Inflation Persistence: Comments on the Conference on "Quantitative Evidence on Price Determination"." Journal of Money, Credit and Banking, Supplement to Vol. 39, No. 1, pp. 203-210. 


\section{Appendix A: Derivation of the Wage}

For simplicity, let the real wage $w_{t}$ be the outcome of a Nash bargain between the median insider and her firm. The median insider faces no risk of dismissal at the negotiated wage. The wage is renegotiated in each period $t$. Under bargaining agreement, the insider receives the wage $w_{t}$ and the firm receives the expected profit $\left(a^{I}-w_{t}\right)$ in each period $t$. Thus the expected present value of the insider's utility $V_{t}^{I}$ under bargaining agreement is

$$
V_{t}^{I}=\frac{w_{t}^{1-\sigma}}{1-\sigma}+\delta\left(\left(1-\phi_{t+1}\right) V_{t+1}^{I}+\phi_{t+1} V_{t+1}^{S}\right)
$$

where $\phi_{t+1}$ is the firing rate and $V_{t+1}^{S}$ the expected utility present value of a short-term unemployed workers' returns. The expected present value of firm's returns under bargaining agreement are

$$
\Pi_{t}^{I}=\left(a_{t}^{I} p_{z}-w_{t}-a_{t} \varepsilon^{I}\right)+\delta\left(\left(1-\phi_{t+1}\right) \Pi_{t+1}^{I}-\phi_{t+1} a_{t+1} f_{t+1}\right)
$$

where $a_{t+1} f_{t+1}$ are firing costs.

Under disagreement, the insider's fallback income is $b_{t}$, assumed for simplicity to be equal to the unemployment benefit. The firm's fallback profit is zero, i.e. during disagreement there is not production. Assuming that disagreement in the current period does not affect future returns, the present values of utility under disagreement for the insider are

$$
V_{t}^{\prime I}=\frac{b_{t}^{1-\sigma}}{1-\sigma}+\delta\left(\left(1-\phi_{t+1}\right) V_{t+1}^{I}+\phi_{t+1} V_{t+1}^{S}\right)
$$

and for the firm are

$$
\Pi_{t}^{\prime I}=0+\delta\left(\left(1-\phi_{t+1}\right) \Pi_{t+1}^{I}-\phi_{t+1} a_{t+1} f_{t+1}\right)
$$

Thus, the insider's bargaining surplus is

$$
\begin{aligned}
V_{t}^{I}-V_{t}^{I I} & =\frac{w_{t}^{1-\sigma}}{1-\sigma}+\delta\left(\left(1-\phi_{t+1}\right) V_{t+1}^{I}+\phi_{t+1} V_{t+1}^{S}\right) \\
& -\frac{b_{t}^{1-\sigma}}{1-\sigma}-\delta\left(\left(1-\phi_{t+1}\right) V_{t+1}^{I}+\phi_{t+1} V_{t+1}^{S}\right) \\
& =\frac{w_{t}^{1-\sigma}-b_{t}^{1-\sigma}}{1-\sigma}
\end{aligned}
$$

and the firm's surplus is

$$
\begin{aligned}
\Pi_{t}^{I}-\Pi_{t}^{I I} & =a_{t}^{I} p_{z}-w_{t}-a_{t} \varepsilon^{I}+\delta\left(\left(1-\phi_{t+1}\right) \Pi_{t+1}^{I}-\phi_{t+1} a_{t+1} f_{t+1}\right)- \\
& \left(\delta\left(\left(1-\phi_{t+1}\right) \Pi_{t+1}^{I}-\phi_{t+1} a_{t+1} f_{t+1}\right)\right) \\
& =a_{t}^{I} p_{z}-w_{t}-a_{t} \varepsilon^{I}
\end{aligned}
$$

The negotiated wage maximizes the Nash product $(\Lambda)$ : 


$$
\Lambda=\left(\frac{w_{t}^{1-\sigma}-b_{t}^{1-\sigma}}{1-\sigma}\right)^{\gamma}\left(a_{t}^{I} p_{z}-w_{t}-a_{t} \varepsilon^{I}\right)^{1-\gamma},
$$

where $\gamma$ represents the bargaining strength of the insider relative to the firm. Thus, the following relationship holds:

$$
\begin{aligned}
\frac{\partial \Lambda}{\partial w_{t}}= & \gamma\left(\frac{w_{t}^{1-\sigma}-b_{t}^{1-\sigma}}{1-\sigma}\right)^{\gamma-1}\left(w_{t}\right)^{-\sigma}\left(a_{t}^{I} p_{z}-w_{t}-a_{t} \varepsilon^{I}\right)^{1-\gamma}+ \\
& \left(\frac{w_{t}^{1-\sigma}-b_{t}^{1-\sigma}}{1-\sigma}\right)^{\gamma}(1-\gamma)\left(a_{t}^{I} p_{z}-w_{t}-a_{t} \varepsilon^{I}\right)^{-\gamma}=0 \\
\Rightarrow & \gamma\left(a_{t}^{I} p_{z}-w_{t}-a_{t} \varepsilon^{I}\right)\left(w_{t}\right)^{-\sigma}+\left(\frac{w_{t}^{1-\sigma}-b_{t}^{1-\sigma}}{1-\sigma}\right)(1-\gamma)=0 \\
\Rightarrow & (1-\gamma)\left(\frac{w_{t}^{1-\sigma}-b_{t}^{1-\sigma}}{1-\sigma}\right)=\gamma\left(a_{t}^{I} p_{z}-w_{t}-a_{t} \varepsilon^{I}\right)\left(w_{t}\right)^{-\sigma}
\end{aligned}
$$

\section{Appendix B: Set of Equations}

To the convenience of the reader, the main equations of the model shall be repeated here. We have 13 endogenous variables: $c, y, v_{h}, \eta, v_{f}, \phi, n, w, p_{z}, \pi$, $\Xi_{t}^{e}, \Xi_{t}^{i}, i$ and the 13 equations are:

$$
\begin{aligned}
c_{t} & =c_{t+1}\left(\left(1+i_{t}\right) \beta E_{t} \frac{1}{\pi_{t+1}}\right)^{-\frac{1}{\sigma}} \\
y_{t} & =a_{t} n_{t} \\
a_{t} h_{t} & =a_{t} p_{z, t}-w_{t}-a_{t} v_{h, t}+\beta E_{t}\left(\tilde{\Pi}_{I, t+1}\right) \\
\eta_{t} & =\Gamma\left(v_{h, t}\right) \\
-a_{t} f_{t} & =a_{t} p_{z, t}-w_{t}-a_{t} v_{f, t}+\beta E_{t}\left(\tilde{\Pi}_{I, t+1}\right) \\
\phi_{t} & =1-\Gamma\left(v_{f, t}\right) \\
n_{t} & =n_{t-1}\left(1-\phi_{t}-\eta_{t}\right)+\eta_{t} \\
\frac{w_{t}^{1-\sigma}-b_{t}^{1-\sigma}}{1-\sigma} & =\frac{1-\gamma}{\gamma}\left(a_{t}^{I} p_{z}-w_{t}-a_{t} \varepsilon^{I}\right)\left(w_{t}\right)^{-\sigma} \\
0 & =(1-\varepsilon) \Delta_{t}+\varepsilon \Delta_{t} p_{z, t}-\Delta_{t} \Psi\left(\pi_{t}-\pi\right) \pi_{t}+\Delta_{t+1} \Psi \beta_{t+1}\left(\pi_{t+1}-\pi\right) \frac{Y_{t+1}}{Y_{t}} \pi_{t+1} \\
c_{t} & =y_{t}-n_{t} \phi f_{t} a_{t}-\left(1-n_{t}\right) \eta_{t} h_{t} a_{t}-(1-\phi) n_{t} a_{t}\left(1-\Xi_{t}^{i}\right)-\left(1-n_{t}\right) \eta_{t} a_{t}\left(1-\Xi_{t}^{e}\right) \\
\Xi_{t}^{e} & =\frac{\int_{-\infty}^{v_{h}} \epsilon_{t} f\left(\epsilon_{t}\right) d \epsilon_{t}}{\eta_{t}} \\
\Xi_{t}^{i} & =\frac{\int_{-\infty}^{v_{f}} \epsilon_{t} f\left(\epsilon_{t}\right) d \epsilon_{t}}{1-\phi_{t}} \\
\frac{1+i_{t}}{1+\bar{\imath}} & =\left(\frac{\pi_{t}}{\bar{\pi}}\right)^{\alpha_{\pi}}\left(\frac{y_{t}}{y}\right)^{\alpha_{y}} e^{\lambda_{t}}
\end{aligned}
$$




\section{Appendix C: The Model under Calvo Price Setting}

Of course, it is also possible to model our approach using Calvo price setting. Let's assume that instead of facing a quadratic price adjustment cost, a wholesale-sector firms can reset its price without any cost but only with an exogenous probability $1-\theta$, while otherwise the price remains unchanged. Once a firm is allowed to change its price, it sets the price to maximize real profits subject to demand (equation 18). Thus, the problem of a price-resetting firm is:

$$
\begin{aligned}
\tilde{\Pi}_{W, t} & =\max _{P_{t}^{*}} E_{t} \sum_{j=0}^{\infty} \theta^{j} \Delta_{t, t+j}\left[\frac{P_{t}^{*}}{P_{t+j}} y_{i, t+j}-t c_{t+j}\left(y_{i, t+j}\right)\right], \\
\text { s.t. } \quad y_{i, t+j} & =\left(\frac{P_{t}^{*}}{P_{t+j}}\right)^{-\varepsilon} y_{t+j},
\end{aligned}
$$

where $P_{t}^{*}$ denotes the optimal reset price of producer $i, t c_{t+j}\left(y_{i, t+j}\right)=\frac{P_{z, t+j}}{P_{t+j}} y_{i, t+j}$ the real total cost function and $\Delta_{t, t+j}$ is the consumption weighted discount factor. The solution to this problem yields the familiar formula for the optimal resetted price in a Calvo setup:

$$
P_{t}^{*}=\left(\frac{\varepsilon}{\varepsilon-1}\right) \frac{E_{t} \sum_{j=0}^{\infty} \theta^{j} \Delta_{t, t+j}\left[P_{t+j}^{\varepsilon} y_{t+j} m c_{i, t+j}\right]}{E_{t} \sum_{j=0}^{\infty} \theta^{j} \Delta_{t, t+j}\left[P_{t+j}^{\varepsilon-1} y_{t+j}\right]},
$$

where $m c_{i, t+j}=\frac{P_{z, t+j}}{P_{t+j}}$ denotes the real marginal costs function.

In case of Calvo price setting, the evolution of the price level is given:

$$
1=\left[\theta \pi_{t}^{\varepsilon-1}+(1-\theta)\left(\frac{P_{t}^{*}}{P_{t}}\right)^{1-\varepsilon}\right]^{\frac{1}{1-\varepsilon}} .
$$

Combining equations (27) and (28) and log-linearizing around the zero inflation steady state can yield exactly the same Phillips curve as the model with Rotemberg adjustment costs (up to a first-order Taylor approximation). ${ }^{48}$

${ }^{48}$ The following relationship has to hold: $\Psi=\frac{(\varepsilon-1) \theta}{(1-\theta)(1-\beta \theta)}$. 